\title{
Unique Features of Subcortical Circuits in a Macaque Model of Congenital Blindness
}

\author{
Loïc Magrou ${ }^{1}$, Pascal Barone ${ }^{2,3}$, Nikola T. Markov ${ }^{4}$, Gwylan Scheeren ${ }^{5}$, \\ Herbert P. Killackey ${ }^{6}$, Pascale Giroud ${ }^{1}$, Michel Berland ${ }^{1}$, Kenneth Knoblauch ${ }^{1}$, \\ Colette Dehay ${ }^{1}$ and Henry Kennedy ${ }^{1,7}$
}

${ }^{1}$ Univ Lyon, Université Claude Bernard Lyon 1, Inserm, Stem Cell and Brain Research Institute U1208, 69500

Bron, France ${ }^{2}$ Université De Toulouse Paul Sabatier, 31062 Toulouse, France ${ }^{3}$ Centre De Recherche Cerveau \& Cognition, CNRS, UMR 5549, 31059 Toulouse, France ${ }^{4}$ Princeton Neuroscience Institute and Department of Psychology, Princeton University, Princeton, 08544, USA ${ }^{5}$ Swammerdam Institute for Life Sciences, Center for Neuroscience, University of Amsterdam, 1090 GE, Amsterdam, The Netherlands ${ }^{6}$ Department of Neurobiology and Behavior, University of California, Irvine, CA 92717, USA, and ${ }^{7}$ Institute of Neuroscience, State Key Laboratory of Neuroscience, Chinese Academy of Sciences Key Laboratory of Primate Neurobiology, Shanghai 200031, China

Address correspondence to Henry Kennedy, Univ Lyon, Université Claude Bernard Lyon 1, Inserm, Stem Cell and Brain Research Institute U1208, 69500 Bron, France. Email: henry.kennedy@inserm.fr; colette.dehay@inserm.fr

\begin{abstract}
There is an extensive modification of the functional organization of the brain in the congenital blind human, although there is little understanding of the structural underpinnings of these changes. The visual system of macaque has been extensively characterized both anatomically and functionally. We have taken advantage of this to examine the influence of congenital blindness in a macaque model of developmental anophthalmia. Developmental anophthalmia in macaque effectively removes the normal influence of the thalamus on cortical development leading to an induced "hybrid cortex (HC)" combining features of primary visual and extrastriate cortex. Here we show that retrograde tracers injected in early visual areas, including $\mathrm{HC}$, reveal a drastic reduction of cortical projections of the reduced lateral geniculate nucleus. In addition, there is an important expansion of projections from the pulvinar complex to the HC, compared to the controls. These findings show that the functional consequences of congenital blindness need to be considered in terms of both modifications of the interareal cortical network and the ascending visual pathways.
\end{abstract}

Key words: connectivity, deafferentation, hybrid cortex, primate, pulvinar

\section{Introduction}

There is a major functional reorganization of the cortex during development in the congenitally blind human. Braille reading has been shown to activate the primary visual cortex, area V1, in early blind individuals (Sadato et al. 1996; Cohen et al. 1997; Buchel et al. 1998). In addition, the visual cortex of the congenitally blind has been observed to support higher cognitive functions including language and numerical processing (Cohen et al. 1997; Roder et al. 2002; Amedi et al. 2004; Bedny et al. 2011; Burton et al. 2012; Watkins et al. 2012; Kanjlia et al. 2016; Crollen et al. 2019). It has been hypothesized that such functional reorganizations reflect a global metamodal cortical 
function, where computations are defined by a particular local network, and where the reorganized brain function reflects a conserved cortical structure accommodating the changes in the inputs from the sensory periphery. Hence according to this theory, developmental deafferentation could induce a higher cognitive function in an early area of the visual cortex by the accommodation of possibly innately determined, long-distance inputs (Pascual-Leone and Hamilton 2001; Sur and Leamey 2001; Merabet and Pascual-Leone 2010; Bedny 2017; Amalric et al. 2018).

In contrast to the metamodal theory, there is ample evidence from invasive animal experimentation that deafferentation during development leads to widespread changes in the adult brain. Recent work in mouse using genetic deletion has allowed major advances in understanding how modification of input from the sensory periphery shapes the identity of cortical neurons ( $\mathrm{Chou}$ et al. 2013; Pouchelon et al. 2014) as well as that of thalamic nuclei (Frangeul et al. 2016). Although the plastic changes that underpin cross-modal compensation are not fully understood, it is generally agreed that they engage activity-dependent processes during brain development (Bavelier and Neville 2002; Ruthazer and Cline 2004). Genetic deletion studies in rodent provide a conceptual framework for interpreting the developmental plasticity and cross-modal plasticity (Frangeul et al. 2016). Further, studies in human provide strong evidence of a reorganization of the large-scale network in the cortex of the congenitally blind. Whole-brain networks of cortical thickness in sighted and early blind individuals suggest that the congenital blind exhibit an extensive reorganization of anatomical networks defined in this manner (Hasson et al. 2016). More recently this issue has been addressed in a macaque model of congenital blindness where anophthalmia is surgically induced in utero by bilateral enucleation (Magrou et al. 2018). This model of congenital blindness builds on earlier investigations, which explored the impact of sensory input from the retina on the specification of the primary visual cortex and where the absence of the retina during development led to part of the primary visual cortex acquiring profound changes in its cytoarchitecture to form a so-called hybrid cortex combining histological and connectivity features of striate and extrastriate cortex (Rakic 1988; Dehay et al. 1989; Dehay et al. 1996a; Dehay et al. 1996b). Investigation of the cortical network in this model of congenital blindness showed a 6-fold expansion of the spatial extent of local connectivity in the hybrid cortex (HC) and a surprisingly high location of the HC in a computational model of the cortical hierarchy (Magrou et al. 2018). In the anophthalmic, the set of areas projecting to the $\mathrm{HC}$, areas V2 and V4 does not differ from that of normal adult controls, but there is a highly significant increase in the relative cumulative weight of the ventral stream areas input to the early visual areas. These findings show that although occupying the territory that would have become primary visual cortex, the HC exhibits features of a higher-order area, thus reflecting a combination of intrinsic and extrinsic factors on the cortical specification (Rakic 1988; Dehay et al. 1989). Understanding the interaction of these contributing factors will shed light on the neurobiology of blindness.

Are these changes in the cortical network solely responsible for the functional reorganization observed in congenital blindness? Intrigued by the changes in dimensions of the thalamic nuclei in the anophthalmic monkey (Rakic et al. 1991; Dehay et al. 1996a), in the present study we have examined the subcortical projections to the cortex of anophthalmic monkey. This revealed a massive reduction of the projections from the lateral geniculate nucleus to the HC. This reduction of afferents from the major thalamic relay of the visual system was counterbalanced by a significant increase in projections from the pulvinar complex to the HC. The marked changes from the pulvinar to the cortex contrasted with the observations that projections from other nuclei including the intralaminar thalamic nuclei, the amygdala, and the claustrum were similar across experimental and control cases.

\section{Materials and Methods}

We examined the connectivity of the cortex in two 25-day old and one 10-month-old macaque, respectively, that had undergone retinal ablation at E58) and E73 (Table 1). In these three experimental anophthalmic animals, we made six tracer injections (three in the HC, one in area V2, and two in area V4), a fast blue (FB) and a diamidino yellow (DY) injection in each and we compared the results to 10 injections made in 8 adult controls.

\section{Anesthesia and Surgery}

The present study is based on observations following bilateral enucleation performed in three monkey fetuses and contrasted to eight normal controls. The enucleated fetuses were carried to term and after birth injected with retrograde tracers (DY and FB) at different postnatal ages (Table 1). Pregnant cynomolgus monkeys (Macaca fascicularis) received atropine (1.25 mg, i.m.), dexamethasone ( $4 \mathrm{mg}$, i.m.), isoxsuprine ( $2.5 \mathrm{mg}$, i.m.), and chlorpromazine ( $2 \mathrm{mg} / \mathrm{kg}$, i.m.) surgical premedication. They were prepared for surgery under ketamine hydrochloride $(20 \mathrm{mg} / \mathrm{kg}$, i.m) anesthesia. Following intubation, anesthesia was continued with $1-2 \%$ halothane in an $\mathrm{N}_{2} \mathrm{O} / \mathrm{O}_{2}$ mixture (70/30). The heart rate was monitored, and the expired $\mathrm{CO}_{2}$ maintained between $4.5 \%$ and $6 \%$. Body temperature was maintained using a thermostatically controlled heating blanket. Between embryonic day 58 (E58) and E73 and using sterile procedures a midline abdominal incision was made, and uterotomy was performed. The fetal head was exposed, bilateral eye removal performed, and the fetus replaced in the uterus after closing the incisions. The mother was returned to her cage and given an analgesic (visceralgine, $1.25 \mathrm{mg}$, i.m.) twice daily for 2 days. All fetuses were allowed normal development until term (E165).

\section{Injections of Retrograde Tracers}

Identical medication, anesthesia, and monitoring procedures were used as described above. Tracer injections were placed in the $\mathrm{HC}$, area V2 and area V4. Injections were made by means of Hamilton syringes in a stereotypic fashion. Following injections, artificial dura mater was applied, the bone f laps were closed, cemented and the scalp stitched back intoposition.

All injections in the anophthalmic brain were confined to the cortical gray matter (Supplementary Figure S1 and S2). Sideby-side injections in target areas of retrograde tracers revealed the topology of connectivity in source areas. Such side-by-side injections were made in the $\mathrm{HC}$ in the lower part of the medial operculum in case BB181 (Fig. 1), corresponding in normal cortex to area V 1subserving parafoveal visual field (Gattass et al. 1987). In case BB122 a single injection was made in V2 near the lip of the lunate sulcus (Fig. 2) where foveal visual field is represented in the normal cortex (Gattass et al. 1981). Finally, a pair of very large injections was made on the dorsal part of the prelunate 
Table 1 Experimental cases

\begin{tabular}{|c|c|c|c|c|c|c|c|}
\hline Category & Case & $\begin{array}{l}\text { Age at } \\
\text { enucleation }\end{array}$ & $\begin{array}{l}\text { Age at } \\
\text { injection }\end{array}$ & $\begin{array}{l}\text { Age at } \\
\text { perfusion }\end{array}$ & Injection site & Dye & $\begin{array}{l}\text { Plane of } \\
\text { section }\end{array}$ \\
\hline \multirow[t]{6}{*}{ Enucleates } & BB181 LH & E73 & PNM13 & $\begin{array}{l}\text { PNM13 + } 13 \\
\text { days }\end{array}$ & $\mathrm{HC}$ & FB & Parasagital \\
\hline & BB181 LH & E73 & PNM13 & $\begin{array}{l}\text { PNM10 + } 13 \\
\text { days }\end{array}$ & $\mathrm{HC}$ & DY & Parasagital \\
\hline & BB122 LH & E58 & PND16 & PND27 & $\mathrm{HC}$ & DY & Horizontal \\
\hline & BB122 LH & E58 & PND16 & PND27 & $\mathrm{V} 2$ & FB & Horizontal \\
\hline & BB169 LH & E71 & PNM10 & $\begin{array}{l}\text { PNM10 + } 12 \\
\text { days }\end{array}$ & $\mathrm{V} 4$ & FB & Horizontal \\
\hline & BB169 LH & E71 & PNM10 & $\begin{array}{l}\text { PNM10 + } 12 \\
\text { days }\end{array}$ & $\mathrm{V} 4$ & DY & Horizontal \\
\hline \multirow{17}{*}{$\begin{array}{l}\text { Adult } \\
\text { controls }\end{array}$} & M071 LH & & & & V1 & DY & Parasagitta \\
\hline & M071 LH & & & & V1 & FB & Parasagitta \\
\hline & M081 LH & & & & V1 & DY & Horizontal \\
\hline & M085 RH & & & & V1 & DY \& FB & Horizontal \\
\hline & M085 LH & & & & V1 & FB & Horizontal \\
\hline & M088 RH & & & & V1 & FB & Horizontal \\
\hline & M121 RH & & & & V1 & DY & Coronal \\
\hline & M122 RH & & & & $\mathrm{V} 1$ & FB & Coronal \\
\hline & M081 RH & & & & $\mathrm{V} 2$ & FB & Horizontal \\
\hline & M101 LH & & & & V2 & DY & Coronal \\
\hline & M101 RH & & & & $\mathrm{V} 2$ & FB & Coronal \\
\hline & M103 LH & & & & V2 & DY & Coronal \\
\hline & BB119 LH & & & & V4 & DY & Horizontal \\
\hline & BB119 LH & & & & $\mathrm{V} 4$ & FB & Horizontal \\
\hline & M094 LH & & & & V4 & DY & Coronal \\
\hline & M094 LH & & & & V4 & FB & Coronal \\
\hline & M122 LH & & & & $\mathrm{V} 4$ & $\mathrm{FB}$ & Coronal \\
\hline
\end{tabular}

E, embryonic day; PND, postnatal day; PNM, postnatal month.

gyrus (Fig. 3), spanning the central and peripheral representation of area V4 in the normal brain ( $\mathrm{Li}$ et al. 1989).

The full extent of labeled neurons was charted in subcortical strucutures.

\section{Animal Euthanasia}

After 10 to 12 days of recovery that allows optimal retrograde labeling of neurons projecting to the pick-up zone, animals were anesthetised with ketamine $(20 \mathrm{mg} / \mathrm{kg}$, i.m.) followed by a lethal dose of Nembutal $(60 \mathrm{mg} / \mathrm{kg}$, i.p.) and perfused through the heart with a $1.25 \%$ paraformaldehyde and $1.5 \%$ glutaraldehyde solution. After fixation, perfusion was continued with a $10-30 \%$ sucrose solution to provide cryoprotection of the brain.

\section{Data Acquisition}

Depending on the enucleation case, parasagittal (BB181) or horizontal (BB122 and BB169) sections (40- $\mu \mathrm{m}$ thick) were cut on a freezing microtome and at least 1 in 3 sections were stained for Nissl substance. Controls were cut in horizontal and coronal planes. Sections were observed in UV light with oil-immersion objectives using a Leitz fluorescence microscope equipped with a D-filter set (355-425 $\mathrm{nm}$ ). High precision maps were made using Mercator software running on Exploranova technology, coupled to the microscope stage. Controlled high-frequency sampling gives stable neuron counts despite the curvature of the cortex and heterogeneity of neuron distribution in the projection zones of individual areas (Vezoli et al. 2004; Markov et al. 2014b) Characteristics of neurons labeled with FB or DY are described by Keizer and colleagues (Keizer et al. 1983). Area limits and layer 4 were marked on the charts of labeled neurons. These neurons were then attributed to areas using our atlas based on landmarks and histology and counted according to that parcellation (Markov et al.2014a).

\section{Statistical Analysis}

All statistical analyses were performed in the R statistical environment (R Development Core Team 2016) with additional tools from the MASS, aods3, and betareg packages (Venables and Ripley 2002; Cribari-Neto and Zeileis 2010; Lesnoff and Lancelot 2012). Each injection gave rise to retrogradely labeled neurons, which were plotted and compared against those of normal animals, injected at anatomically equivalent locations. As previously defined (Markov et al. 2011), the fraction of labeled neurons (FLN) is the proportion of cells located in a given source area with respect to the total number of labeled neurons in the cortex. The connectivity profile is defined by the FLN values for each of the structures labeled from the injected target area.

\section{FLN}

The distribution of FLN values has been successfully modeled previously by a negative binomial distribution (Markov et al. 2011; Markov et al. 2014a). This can be performed using a 
A BB181 LH - Injection HC
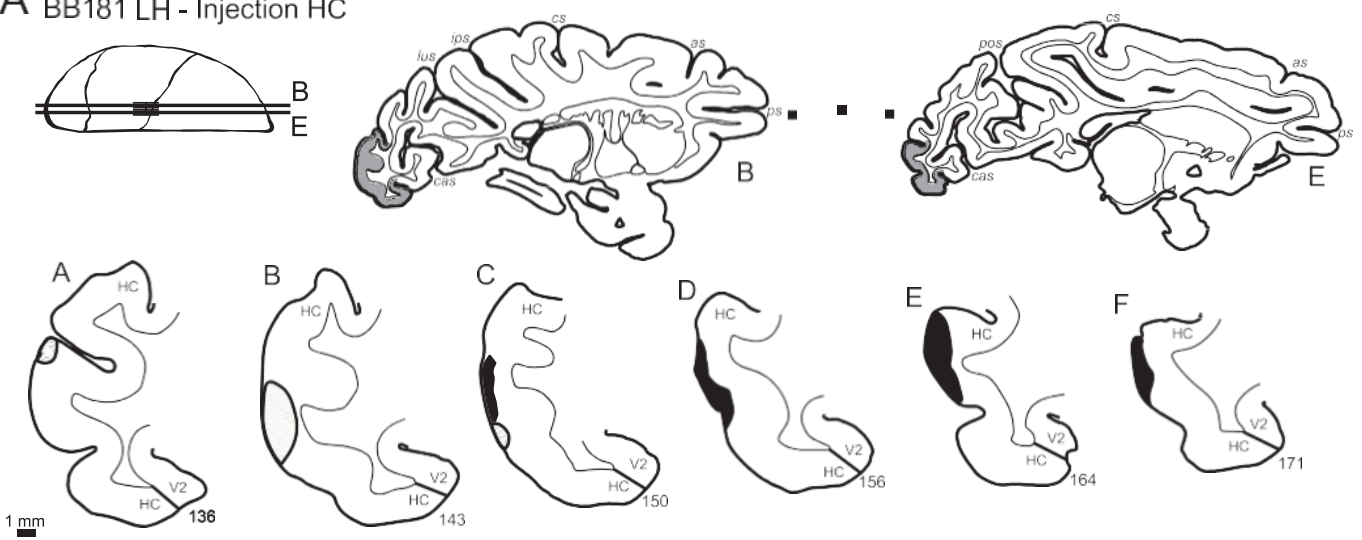

B M71 RH - Injection V1
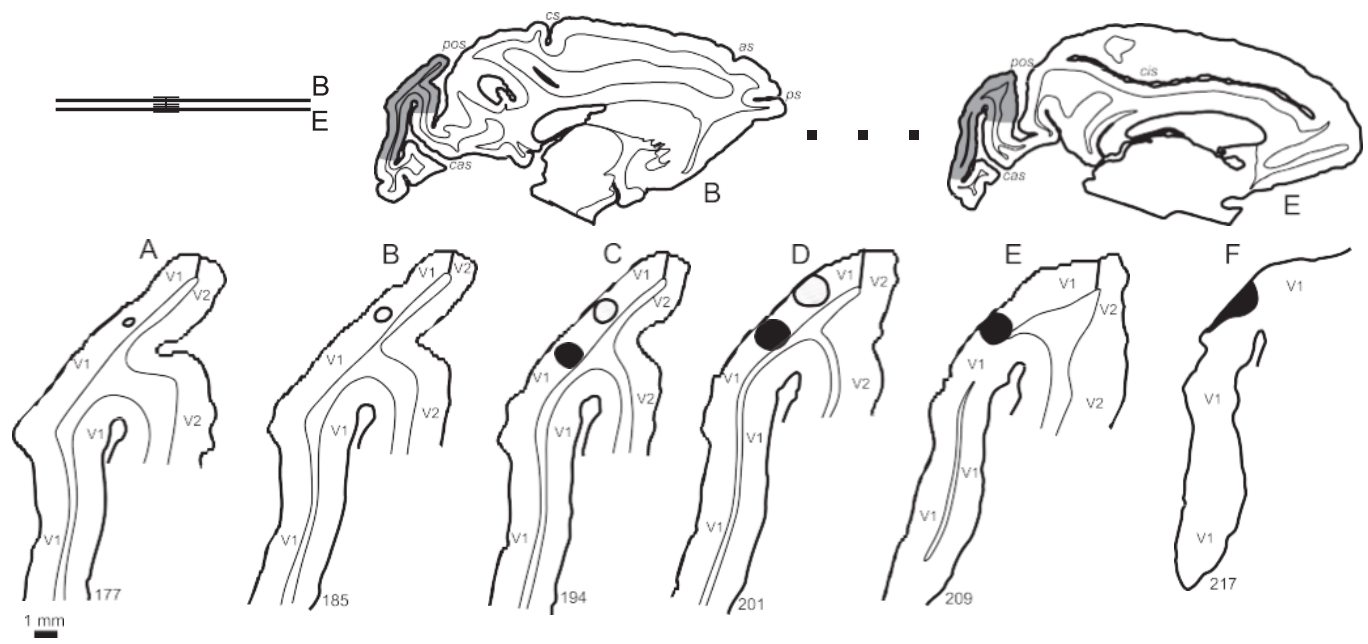

Figure 1. Anatomical drawings showing the injection sites in area V1 in the normal brain and in HC in the anophthalmic brain. ( $A$ ) Tracer injection sites in HC in anophthalmic brain (case BB181LH). Upper-row left cartoons showing the location of sections containing injection sites; right low-power view of sections B and E. Bottom-row numbered sections spanning the injection sites. (B) Tracer injection sites in area V1 in a control (case M071RH). Convention as in (A). Yellow, DY pick-up zone; blue, FB pick-up zone.

generalized linear model (GLM) with a fixed dispersion parameter (McCullagh and Nelder 1989). In brief, the logarjkm of raw neuron counts obtained from each area enter the model as a response variable and the logarithm of the total humber of labeled neurons across all areas is used as a fixed offset. In this way, the model coefficients estimate FLN values. The dispersion parameter of the negative binomial serves to capture the overdispersion frequently observed in data based on counts (Scannell et al. 2000; Markov et al. 2011). We initially estimated the dispersion parameter for individual areas obtaining values between 2.2 and 7.2 and for subsequent testing used an average value of 4 . We then fit this model to compare connection strengths (i.e., FLN values) between normal (i.e., nonenucleated) and enucleated animals. As explanatory variables, we used a 2 level factor, Group (Normal/Anophtalmic) and a 2-level factor, Area for the labeled areas projecting on the target injection. The linear predictor in the GLM includes the main effects of both factors and their interaction. Confidence intervals of $95 \%$ were computed to assess the significance of the difference based on the model-fitted estimates.

\section{Results}

In the present study, we report on the subcortical labeling observed following all the six tracer injections performed in three anopthalmics. The marked features following in utero bilateral enucleation that include changes in cortical area dimensions and cytology and the gross reduction of the lateral geniculate nucleus critically depend on the age of enucleation (Dehay et al. 1991; Dehay et al. 1996a; Dehay et al. 1996b). All three experimental cases showed the extensive changes in cortical cytoarchitecture, gross morphology, and connectivity that were reported elsewhere (Magrou et al. 2018). Injections of tracer in anophthalmics and in 12 normal controls were aimed at regions housing areas V1, $\mathrm{V} 2$, and V4. The increase in the number of controls was to increase statistical power in estimations of the quantitative effects of subcortical reorganization in the absence of the retina.

The nonvisual thalamus was examined at high magnification in all three anophthalmics for back-labeled neurons. Overall the 
A BB122 LH - Injection V2
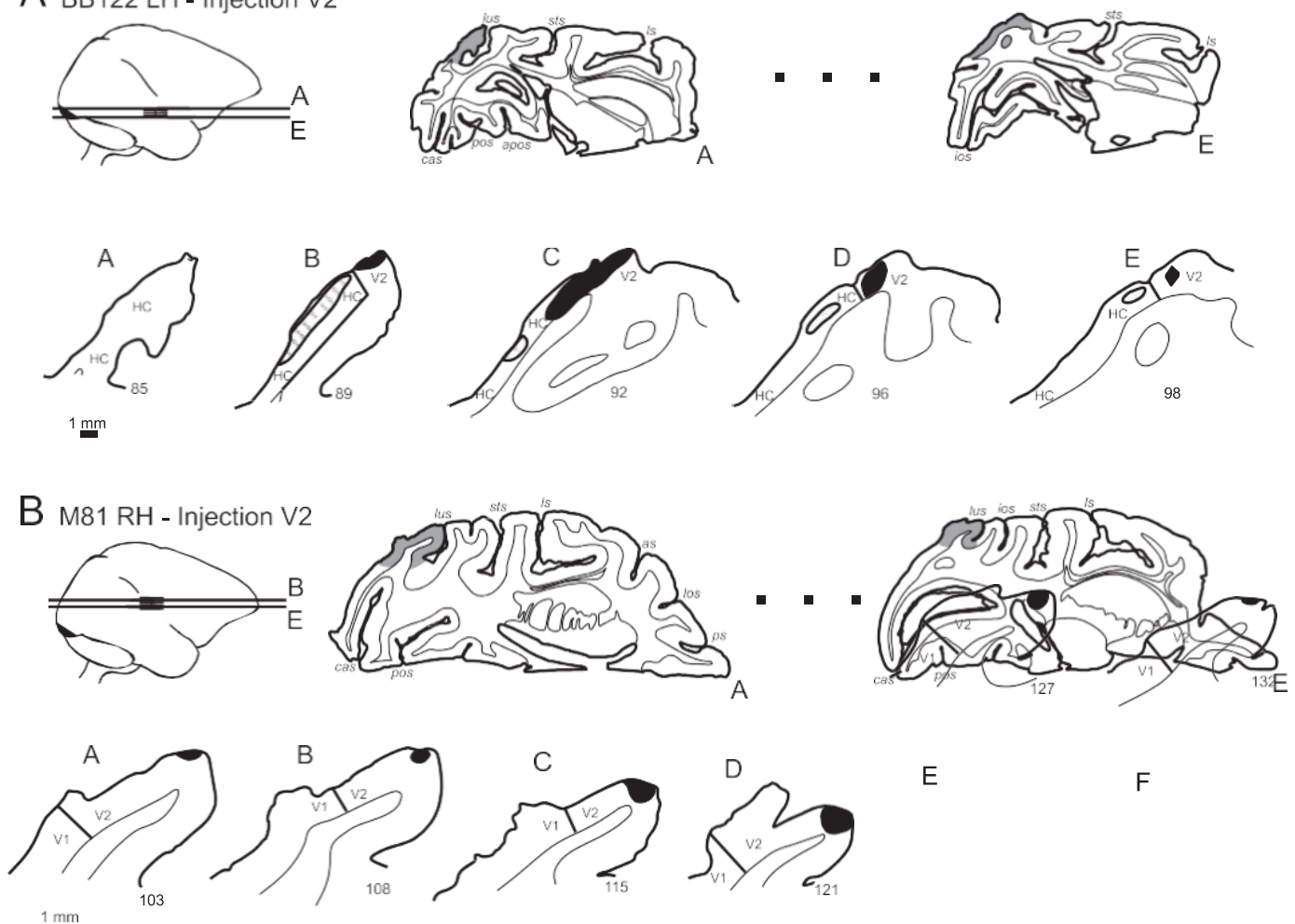

$E$

$\mathrm{F}$

Figure 2. Anatomical drawings showing the injection sites in area V2. (A) Tracer injection sites in area V2 in the anophthalmic brain (case BB122LH). (B) Tracer injection sites in area V2 in a control (case M081RH). Conventions as in Fig. 1.

subcortical structures containing labeled neurons were identical in the experimental and control groups.

\section{Injection Sites}

We describe and quantify the injection sites in controls and experimental cases in order to validate comparing the extent of labeling in subcortical structures. The injections of tracers were made in the region of the cortex that is located on the operculum and that in the normal animal corresponds to area V1 but following early in utero removal of the retina assumes hybrid features combining traits observed normally in areas V1 and V2 (Fig. 1). Injections in presumptive area $\mathrm{V} 2$ were made adjacent and posterior to the lunate sulcus (Fig. 2) and in area V4 on the prelunate gyrus (Fig. 3).

\section{Quantitative Changes in Subcortical Distribution of Labeling}

In Figures 4, 5, and 6 we compare subcortical labeling in controls and anophthalmics following injections in $\mathrm{HC}$ in Figure 4, area V2 in Figure 5 and area V4 in Figure 6. In the illustration of the results, controls have been chosen such that they have the same plane of section as the experimental animals so as to facilitate comparisons of labeling across cases.

One anophthalmic animal received side-by-side injections in the $\mathrm{HC}$ and was sectioned in the parasagittal plane. These injections led to extensive labeling in pulvinar (Fig. 4), where the DY-and FB-labeled neurons were considerably intermingled, in contrast to the labeling in the normal control where in section 148 in Figure $4 B$, the two sets of labeled neurons were tightly grouped but segregated. The extent of the labeled neurons in the anophthalmic was very widespread occupying all of the subdivisions of the pulvinar and hence stretching from the most lateral section containing the pulvinar (section 115 Fig. 4A) to the most medial section (section 143). This strongly contrasted with the control (Fig. 4B), where the lateral-most regions of the pulvinar from sections 134 to 144 were entirely devoid of labeling and where labeling was restricted to sections 146-148. Comparison of the distribution of labeling in the pulvinar of the experimental and control cases shows that injection of $\mathrm{HC}$ leads to considerably more widespread distribution of labeled neurons in lateral, medial, and inferior subdivisions compared to that found following injection in area V1 in controls. It would seem that the additional labeling in the experimental case concerned more extensively the lateral subdivision than the medial subdivision.

Following injection in the HC, outside of the pulvinar, labeling in the greatly reduced lateral geniculate nucleus was extremely limited in the anophthalmic and comparatively extensive in the normal. In the experimental case, labeled lateral geniculate neurons were concentrated on sections 119 , with occasionally labeled neuron retching as far as section 127. As in the pulvinar, the two populations of labeled neurons were once again largely intermingled. These observations in the lateral geniculate nucleus of the anophthalmic contrasted with the observation of a much stronger labeling in the lateral geniculate nucleus of the control, with consistent labeling stretching from 


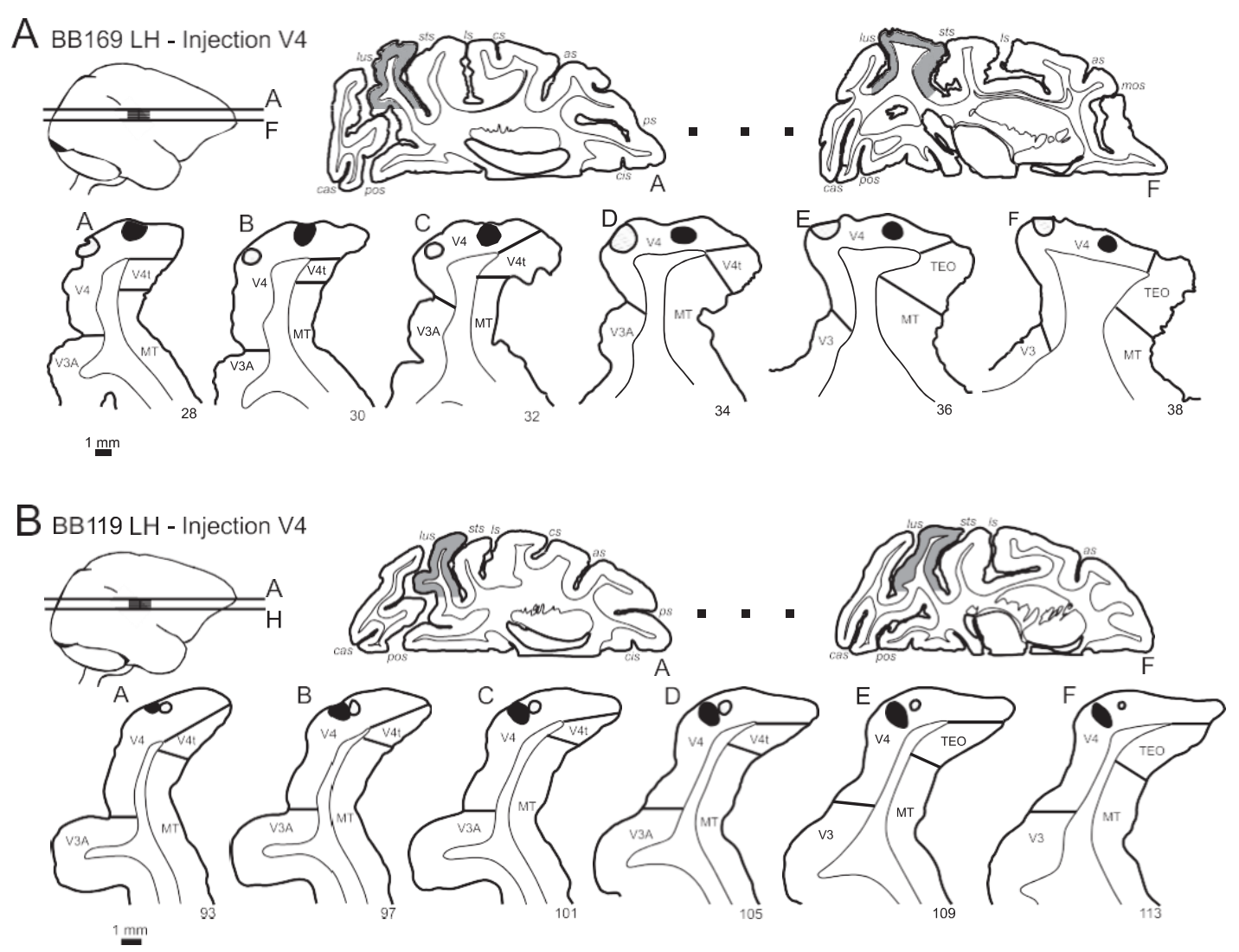

Figure 3. Anatomical drawings showing the injection sites in area V4. (A) Tracer injection sites in area V4 in the anophthalmic brain (case BB169LH). (B) Tracer injection sites in area V4 in the normal control (case BB119LH). Conventions as in Figure 1.

sections 136 to 146 , in which the two populations showed strong segregation forming two adjacent populations on individual sections.

The anophthalmic brain that received an injection of Fast Blue in area V2 was cut in the horizontal plane and showed strong labeling in the pulvinar largely located in the lateral subdivision of the pulvinar and stretching from sections 75 to section 97 (Fig. 5A). In this animal, there was also a DY injection in the $\mathrm{HC}$ that largely coincided with the labeling from the area V2 injection, but was more restricted and largely located in sections 85-89. In this animal, very few labeled neurons were observed in the lateral geniculate nucleus in sections 93 to 103 . Compared to the anophthalmic, labeling in the pulvinar in the control brain shown in Fig. $5 B$ was much more compact and large numbers of labeled neurons were found in the lateral-interior subdivisions in the characteristic $\mathrm{v}$ shape that has been reported elsewhere (Ungerleider et al. 1983; Kennedy and Bullier 1985). Comparison of the distribution of labeling in the pulvinar of the experimental and control cases shows that injection of area V2 in the experimental case leads to a more widespread distribution of labeled neurons in primarily the lateral subdivisions compared to that that found following injection in area V2 in controls.

The anophthalmic brain that received injections of tracer in area V4 had relatively widespread labeling in the pulvinar (Fig. 6A). However, the area V4 control shown in Figure $6 B$ also showed relatively widespread pulvinar labeling with cells from both injections showing intermingling and it was difficult to define a distinct pattern in the anophthalmic with respect to the control. Comparison of the distribution of labeling in the pulvinar of the experimental and control cases shows that injection of area V4 in the experimental case leads to a more widespread distribution of labeled neurons in primarily the lateral subdivisions compared to that found following injection in area V4 in controls.

\section{A Selective Increase in Pulvinar Originating Projections}

The distributions of labeled neurons reported above suggest that there might be significant changes in the weight of subcortical projections of subcortical inputs to the cortex following the removal of the retina. To address this issue, we calculated the FLN for the individual projections (Fig. 7). Side-by-side injections in the HC (BB181) were close enough (less than $1 \mathrm{~mm}$ apart) to be considered a single cumulated injection for the following quantitative analysis (individual values are available in Table 2). This showed a significant increase in the FLN of the pulvinar projection to $\mathrm{HC}$ compared to the pulvinar projection to area $\mathrm{V} 1$ in the normal control. There were no significant differences in the FLN values of the pulvinar projections to either V2 or V4. The projection from the lateral geniculate nucleus was also influenced by the removal of the retina; in the enucleate, compared to the normal control, there was a decrease in the projection of the lateral geniculate projection to area V1 and area V2. Are 
A Enucleated - BB181 LH
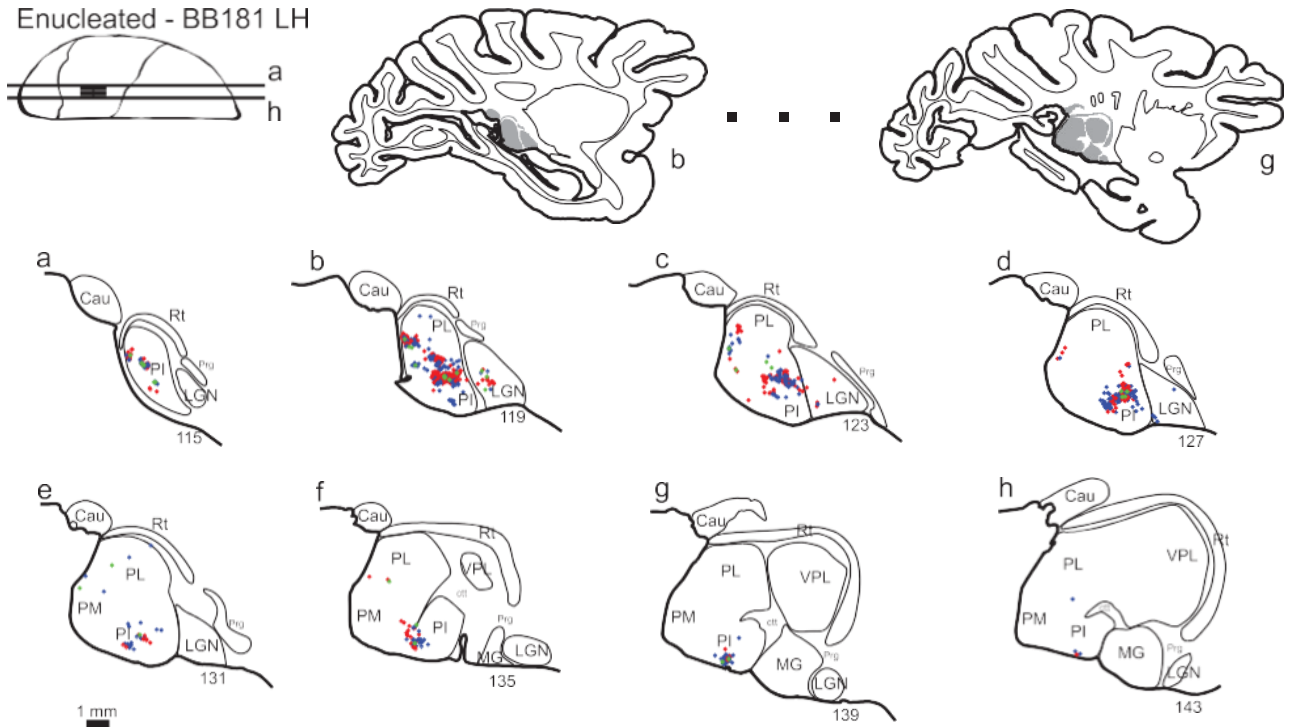

min

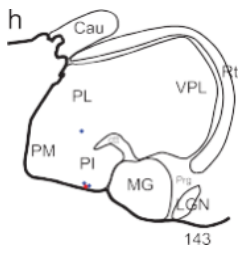

B Normal control - M071 RH
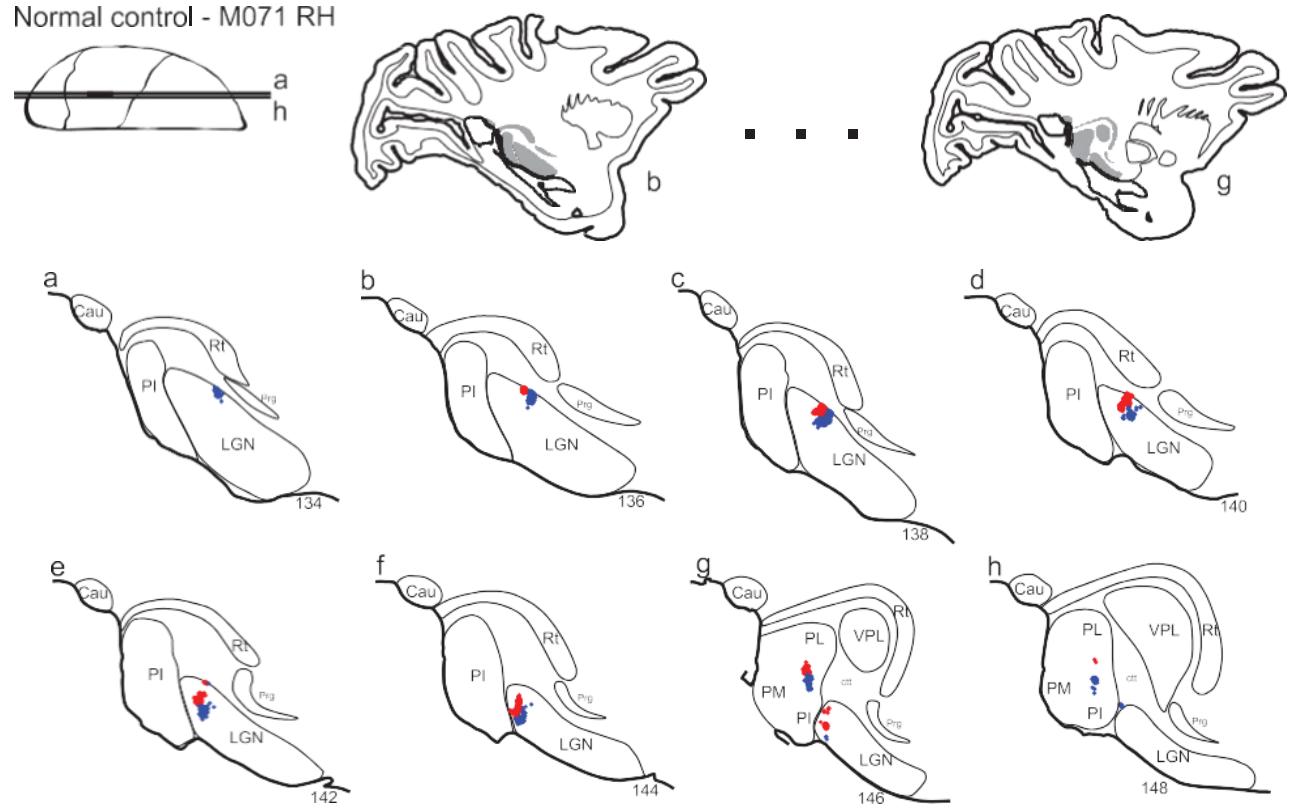

Figure 4. Anatomical drawings showing distributions of labeled cells in subcortical structures following injections in HC/V1. (A) anophthalmic case BB 181LH, side-byside injections in the HC. (B) Corresponding normal control M071RH with a comparable injection site in V1. Blue dots, FB; red dots, DY; green dots, doubly labeled cells. For abbreviations of area names see Glossary.

these changes in the visual thalamus echoed by other changes in subcortical structures projecting to the early visual areas? To address this, we quantified the FLN in claustrum, amygdala, and the intralaminar thalamic nuclei and found no significant differences between control and experimental cases (Fig. 7).

To assess the effect of enucleation on labeling in the pulvinar, illustrated in Figures 4 and 8, we estimated the quantitative spread of labeling in that structure. In each section with pulvinar labeling, the smallest polygon encompassing all marked cells was drawn and its area was computed. The volume of labeling for each case was then interpolated from the series of mea- sured surfaces. To account for the effect of injection size on the labeling spread, the volume of the uptake zone for each case was also measured and used as a covariate in statistical tests. A linear model (LM) was used to test for differences in pulvinar of the volume of labeling spread between normal controls and anophthalmic animals. The cube root of labeling spread volume was taken as the response variable, following a Box-Cox test to assess the best transformation for normality of the data (Box and Cox 1964; Venables and Ripley 2002). For V1/HC, the difference in spread between normal and anophthalmic groups was significant $(P<0.001, t=6.4$, degrees of freedom $(\mathrm{df})=9)$, 

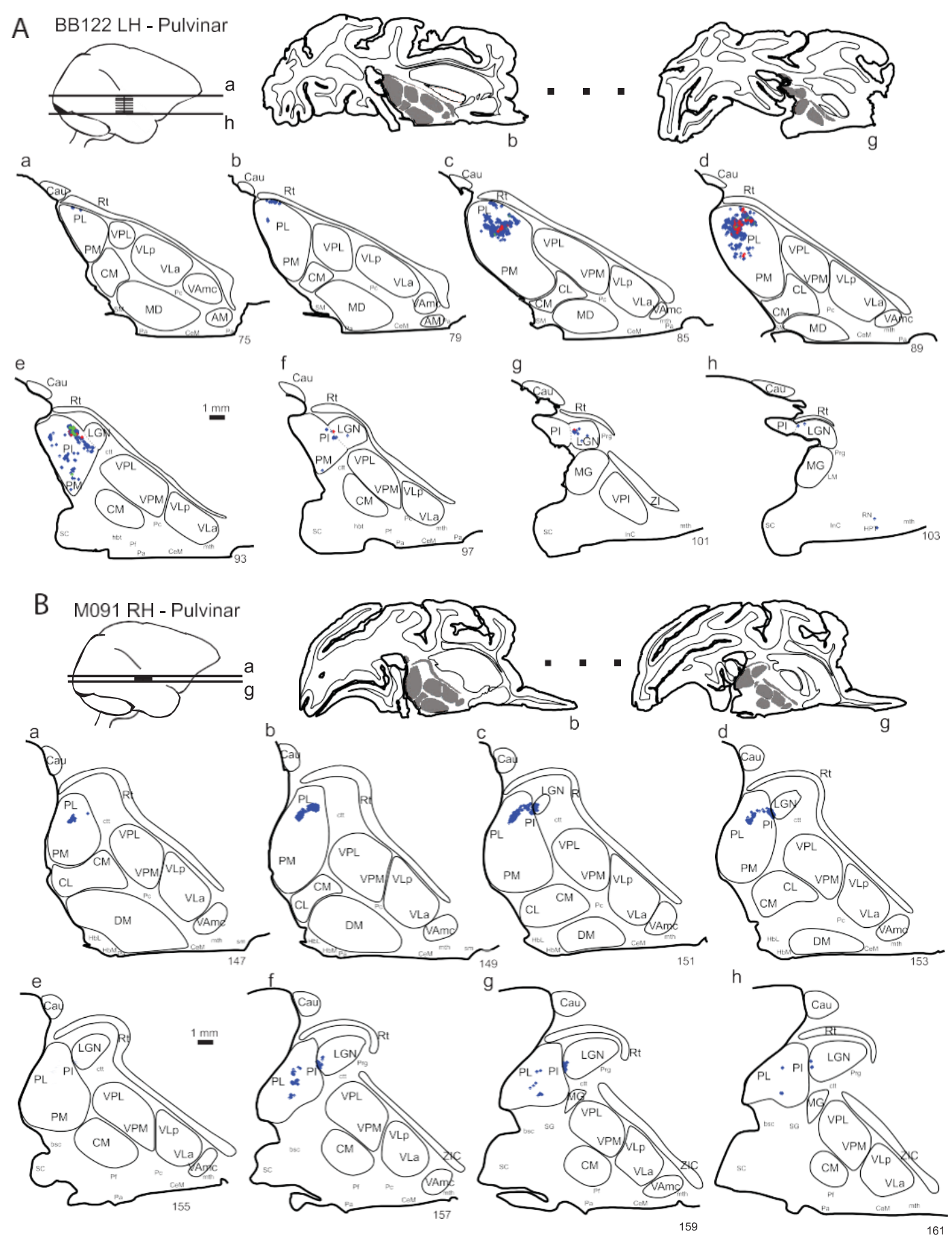

Figure 5. Anatomical drawings showing distributions of labeled cells in subcortical structures following an injection in V2. (A) anophthalmic case BB122LH, single injection in V2. (B) Corresponding normal control M081RH with comparable injection site in V2. See Figure 1 for color coding, for abbreviations of area names see Glossary.

but not for V2 $(P=0.12, t=2.62, \mathrm{df}=2)$ and V4 $(P=0.9, t=-0.09$, $\mathrm{df}=3)$. These results indicate an effect of anophthalmia on the spread of labeling in the pulvinar for $\mathrm{V} 1 / \mathrm{HC}$ but not for $\mathrm{V} 2$ and V4, despite the suggestion in Figure 5 of a differential spread for V2. The enucleated V2 injection, however, is based on a single case and so any test of its difference from the normal is likely to be of low statistical power.
Our results show that in the absence of the retina there is a significant increase in the strength of the projection of the pulvinar to the HC, which is accompanied by a significant increase in the spatial extent of labeling in the pulvinar. The injections in experimental and controls were carried out in a stereotypical fashion. Variations of the uptake zone are not predicted to impact on the FLN values, which are normalized 

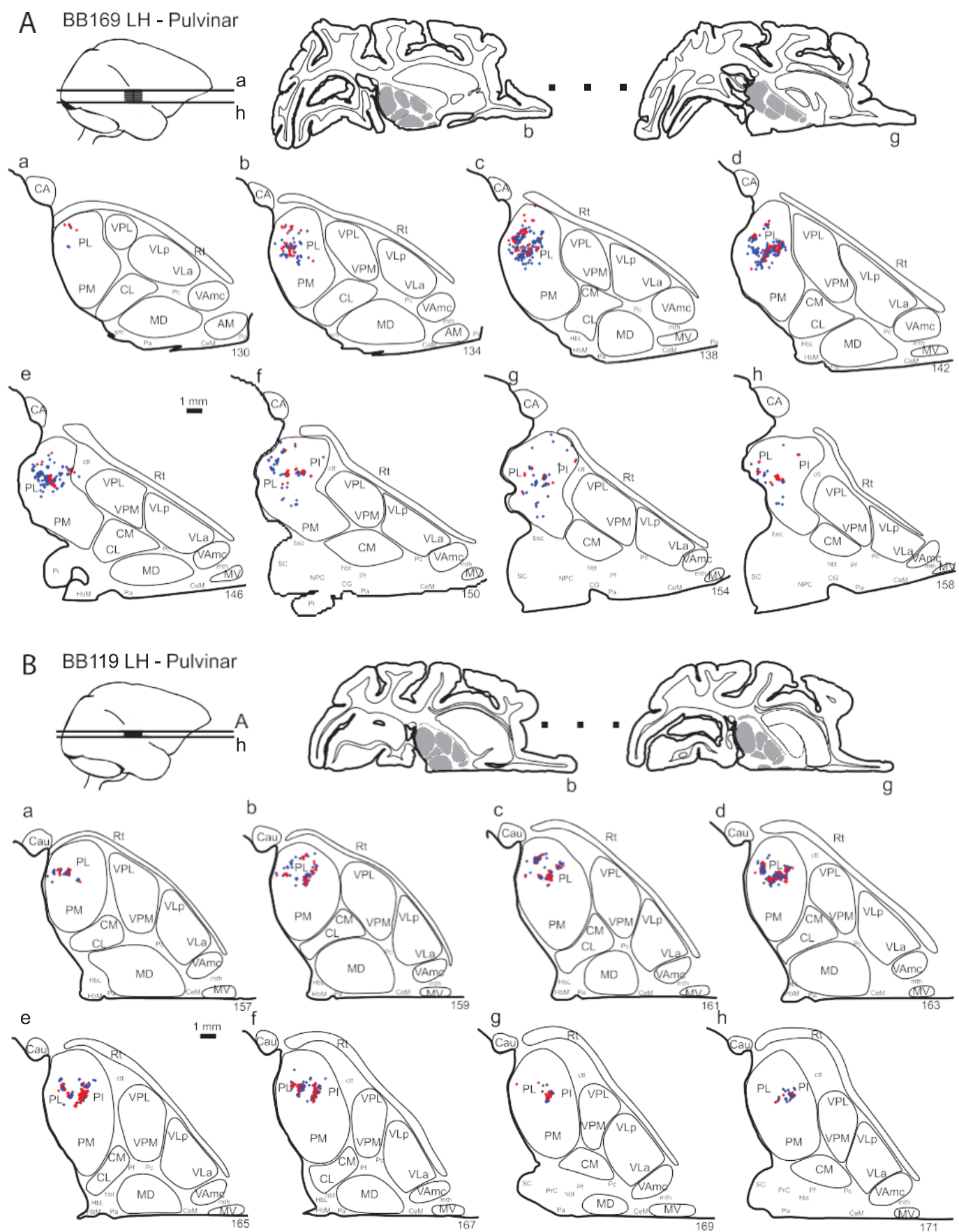

b
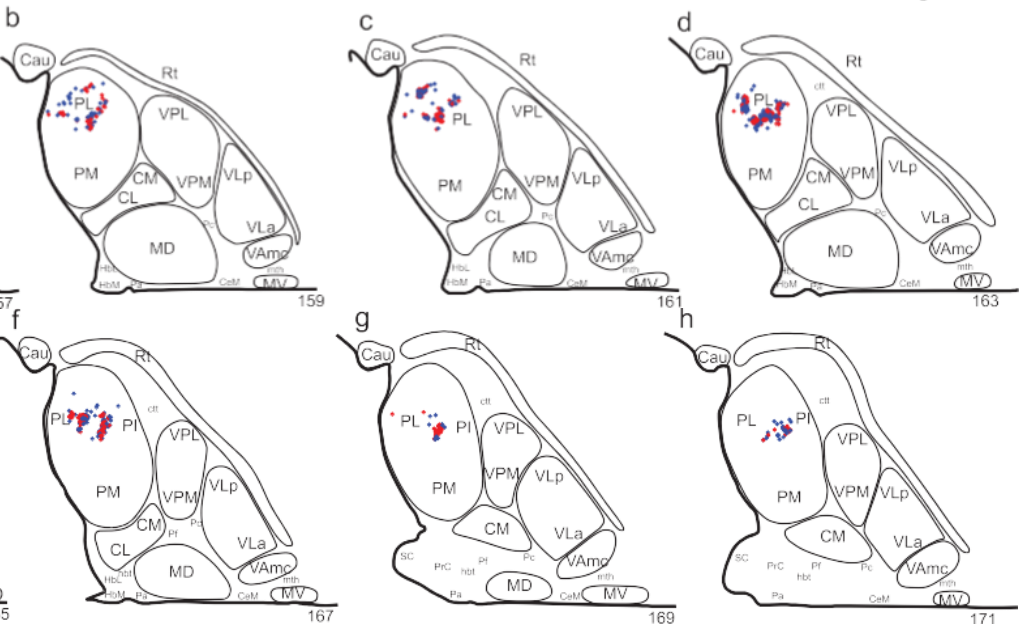

Figure 6. Anatomical drawings showing distributions of labeled cells in subcortical structures following an injection in V2. (A) anophthalmic case BB169LH, side-by-side injections in V4. (B) Corresponding normal control BB119LH with comparable side-by-side injection sites in V4. See Figure 1 for color coding, for abbreviations of area names see Glossary.

with respect to the total number of labeled neurons. However, a variation of the size of the injection and the resulting pickup zone could impact on the spread of labeled neurons that we observe in the pulvinar. To answer this potential concern, we included the size of uptake zones in our analysis of the spread of labeling in the pulvinar as a covariate. Results shown in Figure $8 A$ and respective tests (see $P$ values above) take into account the effect of injection size. Moreover, an analysis of variance could not reject the simple model that size of the uptake zone had no influence on the results. Finally, we compared quantification of the uptake zones, which showed that uptake zones of all injections did not show significant differences.

\section{Discussion}

Subcortical labeling in the anophthalmic brains was quantitatively but not qualitatively different from subcortical labeling in the controls. Although the absence of the retina did not lead 
Table 2 Neuron counts for relevant subcortical structures

\begin{tabular}{|c|c|c|c|c|c|c|c|c|}
\hline & \multicolumn{2}{|c|}{$\begin{array}{c}\mathrm{HC} \\
\text { Enucleated }\end{array}$} & \multicolumn{6}{|c|}{$\begin{array}{c}\text { V1 } \\
\text { Normal }\end{array}$} \\
\hline & BB $122 \mathrm{LH}$ & BB $181 \mathrm{LH}$ & M81LH & M88RH & M121 RH & M85RH & M85LH & M122 RH \\
\hline Pulvinar & 503 & $4492+2850$ & 373 & 89 & 326 & 577 & 336 & 584 \\
\hline LGN & 4 & $167+84$ & 1693 & 476 & 1130 & 1349 & 1577 & 5716 \\
\hline Claustrum & 26 & $2900+3756$ & 1892 & 184 & 213 & 3604 & 4598 & 5260 \\
\hline Amygdala & 23 & $350+434$ & 148 & 36 & 12 & 808 & 246 & 1527 \\
\hline $\begin{array}{l}\text { Intralaminar } \\
\text { nuclei }\end{array}$ & 0 & $50+116$ & NA & NA & NA & 16 & 10 & 386 \\
\hline
\end{tabular}

\begin{tabular}{lllll}
\hline & & \multicolumn{3}{c}{ V2 } \\
\cline { 2 - 5 } & Enucleated & \multicolumn{3}{c}{ Normal } \\
\cline { 2 - 5 } & BB122 LH & M101 LH & M101 RH & M103 LH \\
Pulvinar & 3742 & 3080 & 2128 & 1103 \\
LGN & 20 & 236 & 341 & 302 \\
Claustrum & 3220 & 1838 & 2790 & 3191 \\
Amygdala & 1202 & 36 & 62 & 369 \\
Intralaminar & 422 & 39 & 121 & NA \\
nuclei & & & & \\
\hline
\end{tabular}

\begin{tabular}{lllll}
\hline & & \multicolumn{3}{c}{ V4 } \\
\cline { 2 - 5 } & Enucleated & \multicolumn{3}{c}{ Normal } \\
\cline { 2 - 5 } & BB169 LH & M094 LH & M094 LH & M122 LH \\
Pulvinar & 5224 & 1337 & 1186 & 2169 \\
LGN & NA & 24 & 16 & 20 \\
Claustrum & NA & 2089 & 2647 & 13146 \\
Amygdala & NA & 188 & 290 & 1281 \\
Intralaminar & 58 & 12 & 64 & NA \\
nuclei & & & & \\
\hline
\end{tabular}

V1, primary visual area; V2, secondary visual area, V4, quaternary visual area

to the appearance of novel thalamocortical pathways, it did profoundly modify the strength of the projection from the pulvinar complex, which showed significantly increased numbers of labeled neurons with a spatially expanded distribution. This increase in the pulvinar projection to the $\mathrm{HC}$ was accompanied by a reduction in the projection of the geniculocortical pathway. The expansion of the pulvinar projection to the $\mathrm{HC}$ appeared to be the unique expansion of ascending pathways as quantification of the projections of the claustrum, amygdala, and interlaminar nucleus revealed no differences between experimental and control groups.

\section{Primate and Nonprimate Models of Congenital Blindness}

There have been a number of investigations in congenitally blind rodents that show many similarities with the present findings. Tracers injected to the visual cortex of congenitally anophthalmic mice found point-to-point connectivity in the dorsal lateral geniculate nucleus, and while retrogradely labeled neurons were not reported in nonvisual thalamus there appeared to be an increase in the incidence of labeled neurons in the lateral posterior thalamic nuclei (Godement et al. 1979; Kaiserman-Abramof et al. 1980). Given that the lateral posterior thalamic nucleus is thought to be evolutionarily related to the pulvinar these results in mutant eyeless mice agree with the present findings. Similar findings have been observed in blind mole rats, animals which have adapted to a nonvisual lifestyle (Cooper et al. 1993).

The present findings contrast with those obtained in a recent study on the effects of bilateral enucleation in Mondelphis domestica, a South American marsupial (Kahn and Krubitzer 2002; Karlen et al. 2006). Enucleation at postnatal day 4 led followed by tracers injected in area 17 led to retrograde labeling of neurons in subcortical nuclei associated with somatosensory (ventral posterior nuclei), auditory (medial geniculate nuclei), motor (ventrolateral nucleus) systems and limbic/hippocampal systems (anterior dorsal and anterior ventral nuclei (Karlen and Krubitzer 2009). These findings are very different from what is observed in the anophthalmic monkey where subcortical afferents were restricted to the visual thalamus. A recent study in mouse where geniculocortical pathways were genetically deleted in utero likewise failed to find projections to the visual cortex from nonvisual thalamus (Chou et al. 2013)

The widespread thalamic projections from nonvisual thalamus to the visual cortex in the anophthalmic marsupial brain (Karlen and Krubitzer 2009), not found in the present study, could be due to the differences in developmental timing with respect to retinal ablation. There are two arguments against this hypothesis. Firstly, while the enucleation at 4 th postnatal day 


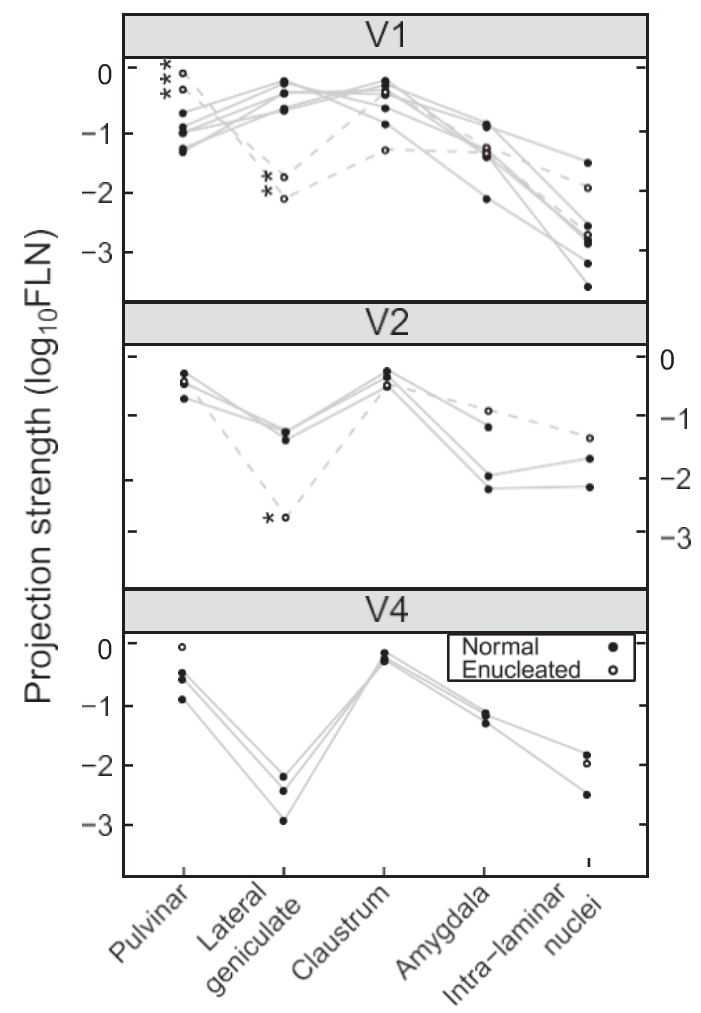

Figure 7. Effect of enucleation on subcortical FLN. Log scale dot plot of FLN. Enucleates, black circles; normal controls, black dots; upper-panel, injections in normal striate cortex (V1) and HC (1anophtalmic, six normals); middle-panel, injections in area V2 (1anophtalmic, three normals); bottom panel, injections in area V4 (two enucleates, three normal). For abbreviations of area names see Glossary.

in the opossum is at an earlier developmental stage than the enucleation in the macaque at embryonic (E) day 70 (Workman et al. 2013), in both species thalamic innervation of the visual cortex is incomplete and generation of supragranular layers has not yet commenced (Rakic 1974; Robinson and Dreher 1990; Finlay and Darlington 1995; Molnar et al. 1998). Secondly, in both species the ages when the retinae were removed lead to profound and very similar modifications of the cortex, with the generation of a novel cortical region referred to as area $\mathrm{X}$ in the marsupial study and $\mathrm{HC}$ in the present and earlier macaque studies (Rakic 1988; Dehay et al. 1989; Kahn and Krubitzer 2002).

The discrepancy between widespread thalamic projections in the anophthalmic opossum and restricted thalamic projections in the anophthalmic macaque (present study) is difficult to explain. It echoes similar differences found in the cortex where nonvisual sensory areas were found to project to the visual cortex in the congenitally blind opossum (Karlen et al. 2006) but not in the congenitally blind macaque (Magrou et al. 2018). Elsewhere we have argued that at the level of the cortex these differences could be due to the stabilization of developmental transient projections that have been observed in the opossum (Karlen et al. 2006), and which do not exist in the developing macaque (Magrou et al. 2018). However, such transient widespread projections from different sensory thalamic nuclei have not been reported in any species and therefore cannot be easily evoked to explain the apparent opossum-macaque differences.

\section{Developmental Specification of the Visual Pathways}

Developmental specification of visual pathways depends on an interplay between genetic and extrinsic mechanisms. Previously, we reported that subsequent to early removal of the retina there were profound modifications of the dimensions, cytology, and connectivity of visual cortical areas cortical areas (Magrou et al. 2018). The areal specification is based on morphogens and secreted signaling molecules and extrinsic inputs relayed to the cortex by thalamocortical axons (O'Leary et al. 2007; De la Rossa et al. 2013; Geschwind and Rakic 2013; Borello et al. 2018). The role of thalamic axons in arealisation is a multistep hierarchical process involving events at progenitor and neuronal levels (Dehay and Kennedy 2007; Chou et al. 2013; Pouchelon and Jabaudon 2014; Moreno-Juan et al. 2017).

The present study finds a considerable modification of the subcortical input to the cortex in an experimental model of blindness resulting from an absence of the retina during in utero development. We examined the input to the cortex in addition to that from the pulvinar from a number of subcortical structures including the amygdala, the claustrum and interlaminar nuclei of the thalamus. We only found a modification of the input to the cortex from the pulvinar. The restriction of change to the projection of the pulvinar could be related to recent findings concerning the timetable of pulvinar innervation of the cortex during development (Bourne and Rosa 2006; Warner et al. 2015; Bourne and Morrone 2017).

In rodent, genetic depletion of the thalamic input to the primary visual area failed to influence the specificity of thalamic projections to the cortex (Chou et al. 2013). These findings support observations in eyeless mice (Godement et al. 1979) suggesting that matching of thalamic inputs to different sensory areas is relatively genetically constrained. There is now considerable evidence that ascending pathways to the cortex in rodents specifies cortical areas. During development genetic deletion of geniculocortical axons suppressed the differentiation of gene expression that distinguishes between area V1 and high-order areas (Chou et al. 2013). More specifically in rodent, thalamocortical axons have been shown to instruct the identity of postsynaptic identity of layer- 4 neurons in a modalityspecific fashion (Pouchelon et al. 2014; Pouchelon and Jabaudon 2014). These ascending influences have also been shown to impact on descending corticothalamic pathways. During normal development, hierarchical wiring ensures that the cortical layers 5 and 6 differentially innervate first-order thalamic nuclei such as the lateral geniculate and higher-order nuclei such as the pulvinar. Loss of the sensory periphery in rodent leads to crosshierarchical corticothalamic rewiring (Grant et al. 2016). In an elegant series of experiments, the team of Denis Jabaudon showed that such cross-hierarchical rewiring could provide a cross-modal genetic framework underlying the development and plasticity of sensory pathways (Frangeul et al. 2016). This work suggests that higher-order thalamic nuclei identity might be a ground state feature and that first-order nuclei identity reflects a periphery input. Because communication across the cortex is ensured by direct cortico-cortical pathways, as well as by corticothalamic-cortical loops, where cortical area interaction is ensured by loops via the higher-order thalamic nuclei (Guillery and Sherman 2002; Sherman 2016), cross-hierarchical rewiring could reflect an adaptive feature underlying evolutionary processes and cross-modal plasticity. With respect to the present findings, the question that now would need to be addressed is whether the modifications of the pulvinar 

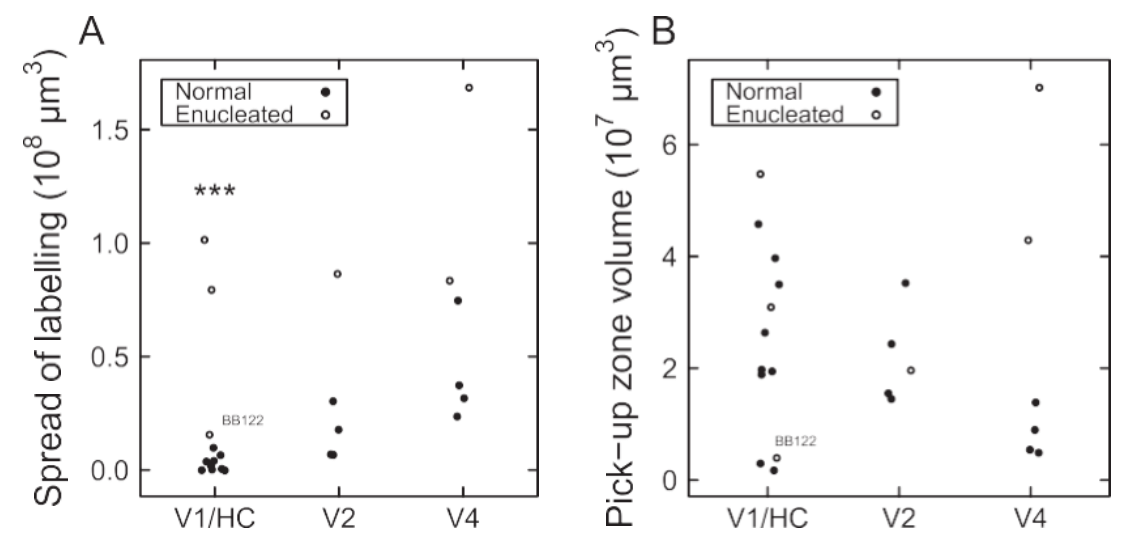

Figure 8. Effect of enucleation on the spread of labeling in the pulvinar. (A) Dot plot of the volume of labeling spread in the Pulvinar. (B) Dot plot of the volume of the matching injection sites. Enucleates, black circles; normal controls, black dots. Injections in V1/HC: three enucleate, nine controls; in area V2: 1anophtalmic, four normals; in area V4: two anophthalmics, four normals. "***” indicates significance with a $P$-value of 0.000126 (see Methods). The case of anophthalmic animal BB122LH is indicated as an outlier for visual reference. For abbreviations of area names, see Glossary.

projection in our experimental animals represent a consequence of a top-down influence.

If the modification of the pulvinar projections to the cortex that we report here are the consequences of top-down processes, why have they not been reported in the numerous lesion experiments that have been carried out in rodents? Elsewhere (Magrou et al. 2018), we speculate that differences in primate and rodent on the role of thalamic afferents to the cortex could reflect the early and prolonged thalamic innervation of the germinal zones in the primate compared to the rodent (Dehay and Kennedy 2007; Dehay et al. 2015).

\section{Relevance of Developmental Effects of Retinal Ablation in Macaque on Congenital Blindness in Human}

Following injection in the HC, the extension of labeled neurons into all subdivisions of the pulvinar in the present results suggests that the projection of the pulvinar to $\mathrm{HC}$ includes regions of the pulvinar that normally project beyond areas $\mathrm{V} 1$ and V2. The fact that the spread appears more extensive into lateral compared to medial subdivisions suggests that the pulvinar expansion in the absence of the retina concerns more territory that normally projects to extrastriate cortical regions than that to frontal regions. Following injection in area V2, the extension of labeling into the lateral subdivision of the pulvinar suggests that territory projecting to the extrastriate cortex was strongly implicated in the expansion of the pulvinar projection to area V2. Nevertheless, the area V2 in the experimental animal showed labeled neurons in the medial pulvinar suggesting that some neurons in the expanded projection concerned territories that would be involved in projections to frontal regions in the normal brain. Following injections in area V4, while there was a suggestion of a possibly greater spread of labeling in the anophthalmic, the location seemed to be grossly comparable in control and experimental brains.

In the anophthalmic macaque the topography of corticocortical connectivity and global organization of the ventral and dorsal streams are largely conserved (Magrou et al. 2018), which is also thought to be the case in human congenitally blind (Pietrini et al. 2004; Ptito et al. 2009; Matteau et al. 2010; Striem-Amitetal. 2012a; Striem-Amit et al. 2012b; Striem-Amit et al. 2015; van den Hurk et al. 2017). These findings support an early developmental specification of the functional streams (Deen

et al. 2017; Livingstone et al. 2017). Further, in the anophtalmic brain, we observe en expansion of the ventral pathway that could reflect cross-modal plasticity (Ptito et al. 2009). However, in addition to the expansion of the ventral stream, there are important differences in the organization of the cortex in the congenitally blind macaque model, notably the extensive intrinsic connectivity of $\mathrm{HC}$ coupled to its high location in the cortical hierarchy. The relatively high position in the cortical hierarchy and the conservation of an extensive local connectivity in the HC could ensure the long-time constants, which would be required for the observed higher cognitive functions of the deafferentated cortex of the blind (Honey et al. 2012; Chaudhuri et al. 2015; Tomasello et al. 2019).

The present results show that in addition to the extensive reorganization of the cortex there are important changes in the projections to HC, namely an important increase in the weight of the projection of the pulvinar and a spatial expansion of cortical projecting neurons in this structure. Although the increase in weight is coherent with findings in eyeless mice, the greatly expanded spatial distribution is more unexpected (Godement et al. 1979). These findings could have a profound impact on cortical processing theories given a current understanding of the role of information processing by the pulvino-cortical interactions (Arcaro et al. 2018).

The understanding of the dynamic role of the pulvinar in orchestrating communication between cortical areas has come to the fore in the last 30 years (Sherman 2018). There is considerable anatomical evidence that areas that share direct cortical connections are also interconnected via their anatomical connections through the pulvinar (Shipp 2003). These cortical pulvinar loops are thought to play a critical role in active visual processing via gating information outflow (Purushothaman et al. 2012) and synchronizing interconnected areas, thereby influencing the allocation of attention (Saalmann et al. 2012). The role of the pulvinar in regulating communication between areas is intrinsically tied to the rich interconnectivity with the cortex. The present findings reveal an important expansion of the neurons projecting to $\mathrm{HC}$ compared to the projection to the normal area V1 (Figs 4 and 8). Because cortical pulvinar loops 
directly depend on the overlapping of the afferent and efferent connections in the pulvinar, the much-enlarged distribution of pulvinar neurons projecting to the $\mathrm{HC}$ is expected to allow communication through a more widespread cortical network in the anophthalmic compared to the controls. Recent work in the Kastner lab suggests that dorsal pulvinar is functionally linked to frontal, parietal and cingulate areas and ventral pulvinar to occipital and temporal regions (Arcaro et al. 2018). Figure 4 shows that whereas in the control there are no labeled neurons in dorsal pulvinar, in the anophthalmic there are numerous labeled neurons in this region. Arcaro et al showed that the cortical coupling in the dorsal pulvinar is relatively insensitive to low-level stimuli and is rather involved in higher-order information integration over extended time windows. These findings suggest that the $\mathrm{HC}$ in the congenitally blind could have an extensive interaction with frontoparietal networks with a broad range of time scales. This would introduce the possibility for information processing which would be eminently suited to its extensive intrinsic connectivity suggesting it could allow neuronal responses over seconds, which we have speculated would be required for the higher cognitive functions of the deafferented cortex of the blind (Honey et al. 2012; Chaudhuri et al. 2015; Magrou et al. 2018).

\section{Conclusion}

The extensive functional reorganization found in the congenitally blind human cortex has led to the expectation that there will be widespread structural changes with the novel, ectopic pathways from different sensory modalities. The macaque model of congenital blindness reported here and elsewhere (Magrou et al. 2018) shows that aside from projections from the subiculum and entorhinal cortex there are no ectopic cortical or subcortical connections to the deafferented cortex. However, given that the interareal network is very dense (Markov et al. 2013), we have taken the precaution of measuring the strength of connections and this shows major changes both in the cortex and in the subcortical projections. The major increase observed in the pulvinar input to the deafferented cortex, along with the modifications that we find in the cortical hierarchy and intrinsic connectivity of $\mathrm{HC}$, could have important functional consequences in the blind brain. The role of corticalsubcortical cortical loops involving higher-order thalamic nuclei in communication across the cortex is now well established. The increased size and spatial spread of the pulvinar projection to hybrid cortex will facilitate communication between far-distant cortical areas, perhaps subserving specific and unique sensorymotor associations in the blind macaque. These long-distance interactions may concern the dorsal and ventral stream, the latter enjoying an increased connectivity with the HC (Magrou et al. 2018).

\section{Funding}

LABEX CORTEX (ANR-11-LABX-0042 to H.K.), Université de Lyon (ANR-11-IDEX-0007 to H.K.), CORE-NETS (ANR-11-BSV4-501 to H.K.), ARCHI-CORE (ANR-14-CE13-0033 to H.K.), CORNET (ANR15-CE32-0016 to H.K.), PRIMACOR (ANR-14-CE13-0036; all operated by the French National Research Agency [ANR]), and FRM Equipe (DEQ20160334943; operated by the Foundation for Medical Research).

\section{Author's Contribution}

$\mathrm{CD}$, HK proposed the project; $\mathrm{PG}, \mathrm{MB}, \mathrm{HK}$ surgical intervention; PB, PG, CD histological processing; LM, PB, NTM, GS, HPK, PG, CD data acquisition; LM, PB, NMT, GS, KK, HK data analysis; KK computational modeling; LM, CD, HK wrote the paper. All authors contributed to editing the final document.

\section{References}

Amalric M, Denghien I, Dehaene S. 2018. On the role of visual experience in mathematical development: evidence from blind mathematicians. Dev Cogn Neurosci. 30:314-323.

Amedi A, Floel A, Knecht S, Zohary E, Cohen LG. 2004. Transcranial magnetic stimulation of the occipital pole interferes with verbal processing in blind subjects. Nat Neurosci. 7:1266-1270.

Arcaro MJ, Pinsk MA, Chen J, Kastner S. 2018. Organizing principles of pulvino-cortical functional coupling in humans. Nat Commun. 9:5382.

Bavelier D, Neville HJ. 2002. Cross-modal plasticity: where and how? Nat Rev Neurosci. 3:443-452.

Bedny M. 2017. Evidence from blindness for a cognitively pluripotent cortex. Trends Cogn Sci. .

Bedny M, Pascual-Leone A, Dodell-Feder D, Fedorenko E, Saxe R. 2011. Language processing in the occipital cortex of congenitally blind adults. Proc Natl Acad Sci U S A. 108:4429-4434.

Borello U, Kennedy H, Dehay C. 2018. The logistics of afferent cortical specification in mice and men. Semin Cell Dev Biol. 76:112-119.

Bourne JA, Morrone MC. 2017. Plasticity of visual pathways and function in the developing brain: is the pulvinar a crucial player? Front Syst Neurosci. 11:3.

Bourne JA, Rosa MG. 2006. Hierarchical development of the primate visual cortex, as revealed by neurofilament immunoreactivity: early maturation of the middle temporal area (MT). Cereb Cortex. 16:405-414.

Box GEP, Cox DR. 1964. An analysis of transformations (with discussion). J Roy Stat Soc B. 26:211-252.

Buchel C, Price C, Frackowiak RS, Friston K. 1998. Different activation patterns in the visual cortex of late and congenitally blind subjects. Brain. 121:409-419.

Burton H, Sinclair RJ, Agato A. 2012. Recognition memory for braille or spoken words: an fMRI study in early blind. Brain Res. 1438:22-34.

Chaudhuri R, Knoblauch K, GarielMA, Kennedy H, Wang XJ.2015. A large-scale circuit mechanism for hierarchical dynamical processing in the primate cortex. Neuron. 88:419-431.

Chou SJ, Babot Z, Leingartner A, Studer M, Nakagawa Y, O'Leary DD. 2013. Geniculocortical input drives genetic distinctions between primary and higher-order visual areas. Science. 340:1239-1242.

Cohen LG, Celnik P, Pascual-Leone A, Corwell B, Falz L, Dambrosia J, Honda M, Sadato N, Gerloff C, Catala MD et al. 1997. Functional relevance of cross-modal plasticity in blind humans. Nature. 389:180-183.

Cooper HM, Herbin M, Nevo E. 1993. Visual system of a naturally microphthalmic mammal: the blind mole rat, SpalaxEhrenbergi. J Comp Neurol. 328:313-350.

Cribari-Neto F, Zeileis A. 2010. Beta regression in R. J Stat Soft. 34:1-24.

Crollen V, Lazzouni L, Rezk M, Bellemare A, Lepore F, Noel MP, Seron X, Collignon O. 2019. Recruitment of the occipital 
cortex by arithmetic processing follows computational bias in the congenitally blind. Neuroimage. 186:549-556.

De la Rossa A, Bellone C, Golding B, Vitali I, Moss J, Toni N, Luscher C, Jabaudon D. 2013. In vivo reprogramming of circuit connectivity in postmitotic neocortical neurons. Nat Neurosci. 16:193-200.

Deen B, Richardson H, Dilks DD, Takahashi A, Keil B, Wald LL, Kanwisher N, Saxe R. 2017. Organization of high-level visual cortex in human infants. Nat Commun. 8: 13995.

Dehay C, Giroud P, Berland M, Killackey H, Kennedy H. 1996a. Contribution of thalamic input to the specification of cytoarchitectonic cortical fields in the primate: effects of bilateral enucleation in the fetal monkey on the boundaries, dimensions, and gyrification of striate and extrastriate cortex. J Comp Neurol. 367:70-89.

Dehay C, Giroud P, Berland M, Killackey HP, Kennedy H. 1996b. Phenotypic characterisation of respecified visual cortex subsequent to prenatal enucleation in the monkey: development of acetylcholinesterase and cytochrome oxidase patterns. J Comp Neurol. 376:386-402.

Dehay C, Horsburgh G, Berland M, Killackey H, Kennedy H. 1989. Maturation and connectivity of the visual cortex in monkey is altered by prenatal removal of retinal input. Nature. 337:265-267.

Dehay C, Horsburgh G, Berland M, Killackey H, Kennedy H. 1991. The effects of bilateral enucleation in the primate fetus on the parcellation of visual cortex. Dev Brain Res. 62: 137-141.

Dehay C, Kennedy H. 2007. Cell-cycle control and cortical development. Nat Rev Neurosci. 8:438-450.

Dehay C, Kennedy H, Kosik KS. 2015. The outer subventricular zone and primate-specific cortical Complexification. Neuron. 85:683-694.

Finlay BL, Darlington RB. 1995. Linked regularities in the development and evolution of mammalian brains. Science. 268:1578-1584.

Frangeul L, Pouchelon G, Telley L, LefortS, Luscher C, Jabaudon D. 2016. A cross-modal genetic framework for the development and plasticity of sensory pathways. Nature. 538:96-98.

Gattass R, Gross CG, Sandell JH. 1981. Visual topography of V2 in the macaque. J Comp Neurol. 201:519-539.

Gattass R, Sousa AP, Rosa MG. 1987. Visual topography of V1 in the Cebus monkey. J Comp Neurol. 259:529-548.

Geschwind DH, Rakic P. 2013. Cortical evolution: judge the brain by its cover. Neuron. 80:633-647.

Godement P, Saillour P, Imbert M. 1979. Thalamic afferents to the visual cortex in congenitally anophthalmic mice. Neurosci Lett. 13:271-278.

Grant E, Hoerder-Suabedissen A, Molnar Z. 2016. The regulation of corticofugal fiber targeting by retinal inputs. Cereb Cortex. 26:1336-1348.

Guillery RW, Sherman SM. 2002. Thalamic relay functions and their role in corticocortical communication: generalizations from the visual system. Neuron. 33:163-175.

Hasson U, Andric M, Atilgan H, Collignon O. 2016. Congenital blindness is associated with large-scale reorganization of anatomical networks. Neuroimage. 128:362-372.

Honey CJ, Thesen T, Donner TH, Silbert LJ, Carlson CE, Devinsky O, Doyle WK, Rubin N, Heeger DJ, Hasson U. 2012. Slow cortical dynamics and the accumulation of information over long timescales. Neuron. 76:423-434.

Kahn DM, Krubitzer L. 2002. Massive cross-modal cortical plasticity and the emergence of a new cortical area in devel- opmentally blind mammals. Proc Natl Acad Sci U S A. 99:11429-11434.

Kaiserman-Abramof IR, Graybiel AM, Nauta WJH. 1980. The thalamic projection to cortical area 17 in a congenitally anophtalmic mouse strain. Neuroscience. 5:41-52.

Kanjlia S, Lane C, Feigenson L, Bedny M. 2016. Absence of visual experience modifies the neural basis of numerical thinking. Proc Natl Acad Sci U S A. 113:11172-11177.

Karlen SJ, Kahn DM, Krubitzer L. 2006. Early blindness results in abnormal corticocortical and thalamocortical connections. Neuroscience. 142:843-858.

Karlen SJ, Krubitzer L. 2009. Effects of bilateral enucleation on the size of visual and nonvisual areas of the brain. Cereb Cortex. 19:1360-1371.

Keizer K, Kuypers HGJM, Huisman AM, Dann O. 1983. Diamidino yellow dihydrochloride (DY 2HCl): a new fluorescent retrograde neuronal tracer, which migrates only very slowly out of the cell. Exp Brain Res. 51:179-191.

Kennedy H, Bullier J. 1985. A double-labeling investigation of the afferent connectivity to cortical areas V1 and V2 of the macaque monkey. J Neurosci. 5:2815-2830.

Lesnoff M, Lancelot R. 2012. aod: Analysis of Overdispersed Data. R package version 13. http://cran.r-project.org/package=aod.

Li CY, Tanaka M, Creutzfeldt OD. 1989. Attention and eye movement related activation of neurons in the dorsal prelunate gyrus (area DP). Brain Res. 496:307-313.

Livingstone MS, Vincent JL, Arcaro MJ, Srihasam K, Schade PF, Savage T. 2017. Development of the macaque face-patch system. Nat Commun. 8: 14897.

Magrou L, Barone P, Markov NT, Killackey HP, Giroud P, Berland M, Knoblauch K, Dehay C, Kennedy H. 2018. How areal specification shapes the local and interareal circuits in a macaque model of congenital blindness. Cereb Cortex. 28: 3017-3034.

Markov NT, Ercsey-Ravasz M, Van Essen DC, Knoblauch K, Toroczkai Z, Kennedy H. 2013. Cortical high-density counterstream architectures. Science. 342: 1238406.

Markov NT, Ercsey-Ravasz MM, Ribeiro Gomes AR, Lamy C, Magrou L, Vezoli J, Misery P, Falchier A, Quilodran R, Gariel MA et al. 2014a. A weighted and directed interareal connectivity matrix for macaque cerebral cortex. Cereb Cortex. 24:1736.

Markov NT, Misery P, Falchier A, Lamy C, Vezoli J, Quilodran R, Gariel MA, Giroud P, Ercsey-Ravasz M, Pilaz LJ et al. 2011. Weight consistency specifies regularities of macaque cortical networks. Cereb Cortex. 21:1254-1272.

Markov NT, Vezoli J, Chameau P, Falchier A, Quilodran R, Huissoud C, Lamy C, Misery P, Giroud P, Barone P et al. 2014b. The anatomy of hierarchy: feedforward and feedback pathways in macaque visual cortex. J Comp Neurol. 522:225-259.

Matteau I, Kupers R, Ricciardi E, Pietrini P, Ptito M. 2010. Beyond visual, aural and haptic movement perception: hMT+ is activated by electrotactile motion stimulation of the tongue in sighted and in congenitally blind individuals. Brain Res Bull. 82:264-270.

McCullagh P, Nelder JA. 1989. Generalized linear models. Boca Raton: Chapman \& Hall/CRC.

Merabet LB, Pascual-Leone A. 2010. Neural reorganization following sensory loss: the opportunity of change. Nat Rev Neurosci. 11:44-52.

Molnar Z, Knott GW, Blakemore C, Saunders NR. 1998. Development of thalamocortical projections in the South American 
gray short-tailed opossum (Monodelphis domestica). J Comp Neurol. 398:491-514.

Moreno-Juan V, Filipchuk A, Anton-Bolanos N, Mezzera C, Gezelius H, Andres B, Rodriguez-Malmierca L, Susin R, Schaad O et al. 2017. Prenatal thalamic waves regulate cortical area size prior to sensory processing. Nat Commun. 8: 14172.

O'Leary DD, Chou SJ, Sahara S. 2007. Area patterning of the mammalian cortex. Neuron. 56:252-269.

Pascual-Leone A, Hamilton R. 2001. The metamodal organization of the brain. Prog Brain Res. 134:427-445.

Pietrini P, Furey ML, Ricciardi E, Gobbini MI, Wu WH, Cohen L, Guazzelli M, Haxby JV. 2004. Beyond sensory images: objectbased representation in the human ventral pathway. Proc Natl Acad Sci U S A. 101:5658-5663.

Pouchelon G, Gambino F, Bellone C, Telley L, Vitali I, Luscher C, Holtmaat A, Jabaudon D. 2014. Modality-specific thalamocortical inputs instruct the identity of postsynaptic L4 neurons. Nature. 511:471-474.

Pouchelon G, Jabaudon D. 2014. Nurturing the cortex's thalamic nature. Curr Opin Neurol. 27:142-148.

Ptito M, Matteau I, Gjedde A, Kupers R. 2009. Recruitment of the middle temporal area by tactile motion in congenital blindness. Neuroreport. 20:543-547.

Purushothaman G, Marion R, Li K, Casagrande VA. 2012. Gating and control of primary visual cortex by pulvinar. Nat Neurosci. 15:905-912.

R Development Core Team. 2016. R: a language and environment for statistical computing. In. Vienna, Austria. R Foundation for Statistical Computing. http://www.R-project.org.

Rakic P. 1974. Neurons in rhesus monkey visual cortex: systematic relation between time of origin and eventual disposition. Science. 183:425-427.

Rakic P. 1988. Specification of cerebral cortical areas. Science. 241:170-176.

Rakic P, Suner I, Williams RW. 1991. A novel cytoarchitectonic area induced experimentally within the primate visual cortex. Proc Natl Acad Sci U S A. 88:2083-2087.

Robinson SR, Dreher B. 1990. The visual pathways of eutherian mammals and marsupials develop according to a common timetable. Brain Behav Evol. 36:177-195.

Roder B, Stock O, Bien S, Neville H, Rosler F. 2002. Speech processing activates visual cortex in congenitally blind humans. Eur J Neurosci. 16:930-936.

Ruthazer ES, Cline HT. 2004. Insights into activity-dependent map formation from the retinotectal system: a middle-ofthe-brain perspective. J Neurobiol. 59:134-146.

Saalmann YB, Pinsk MA, Wang L, Li X, Kastner S. 2012. The pulvinar regulates information transmission between cortical areas based on attention demands. Science. 337:753-756.

Sadato N, Pascual-Leone A, Grafman J, Ibanez V, Deiber MP, Dold G, Hallett M. 1996. Activation of the primary visual cortex by Braille reading in blind subjects. Nature. 380: 526528 .
Scannell JW, Grant S, Payne BR, Baddeley R. 2000. On variability in the density of corticocortical and thalamocortical connections. Philos Trans R Soc Lond B Biol Sci. 355: 2135.

Sherman SM. 2016. Thalamus plays a central role in ongoing cortical functioning. Nat Neurosci. 19:533-541.

Sherman SM. 2018. My prolonged collaboration with Ray Guillery. Eur J Neurosci. 49:928-937.

Shipp S. 2003. The functional logic of cortico-pulvinar connections. Philos Trans R Soc Lond B Biol Sci. 358: 16051624.

Striem-Amit E, Cohen L, Dehaene S, Amedi A. 2012a. Reading with sounds: sensory substitution selectively activates the visual word form area in the blind. Neuron. 76:640-652.

Striem-Amit E, Dakwar O, Reich L, Amedi A. 2012b. The largescale organization of "visual" streams emerges without visual experience. Cereb Cortex. 22:1698-1709.

Striem-Amit E, Ovadia-Caro S, Caramazza A, Margulies DS, Villringer A, Amedi A. 2015. Functional connectivity of visual cortex in the blind follows retinotopic organization principles. Brain. 138:1679-1695.

Sur M, Leamey CA. 2001. Development and plasticity of cortical areas and networks. Nat Rev Neurosci. 2:251-262.

Tomasello R, Wennekers T, Garagnani M, Pulvermuller F. 2019. Visual cortex recruitment during language processing in blind individuals is explained by Hebbian learning. Sci Rep. 9:3579.

Ungerleider LG, Galkin TW, Mishkin M. 1983. Visuotopic organization of projections from striate cortex to inferior and lateral pulvinar in rhesus monkey. J Comp Neurol. 217: 137157.

van den Hurk J, Van Baelen M, Op de Beeck HP. 2017. Development of visual category selectivity in ventral visual cortex does not require visual experience. Proc Natl Acad Sci U S A. 114:E4501-E4510.

Venables WN, Ripley BD. 2002. Modern applied statistics with S. New York: Springer.

Vezoli J, Falchier A, Jouve B, Knoblauch K, Young M, Kennedy H. 2004. Quantitative analysis of connectivity in the visual cortex: extracting function from structure. Neuroscientist. 10:476-482.

Warner CE, Kwan WC, Wright D, Johnston LA, Egan GF, Bourne JA. 2015. Preservation of vision by the pulvinar following early-life primary visual cortex lesions. Curr Biol. 25: 424434.

Watkins KE, Cowey A, Alexander I, Filippini N, Kennedy JM, Smith SM, Ragge N, Bridge H. 2012. Language networks in anophthalmia: maintained hierarchy of processing in 'visual' cortex. Brain. 135:1566-1577.

Workman AD, Charvet CJ, Clancy B, Darlington RB, Finlay BL. 2013. Modeling transformations of neurodevelopmental sequences across mammalian species. J Neurosci. 33:7368-7383. 